\title{
Validation of a gold standard method for iodine quantification in raw and processed milk, and its variation in different dairy species
}

\author{
G. Niero, ${ }^{1}$ M. Franzoi, ${ }^{1}$ V. Vigolo, ${ }^{1 *}$ M. Penasa, ${ }^{1}$ M. Cassandro, ${ }^{1}$ C. Boselli, ${ }^{2}$ G. Giangolini, ${ }^{2}$ and M. De Marchi ${ }^{1}$ \\ ${ }^{1}$ Department of Agronomy, Food, Natural Resources, Animals and Environment, University of Padova, Viale dell'Università 16, \\ 35020 Legnaro (PD), Italy \\ ${ }^{2}$ Istituto Zooprofilattico Sperimentale del Lazio e della Toscana "M. Aleandri"-National Reference Centre for Ovine and Caprine Milk \\ and Dairy Products Quality (CReLDOC), Via Appia Nuova 1411, 00178 Rome, Italy
}

\section{ABSTRACT}

Adequate milk consumption significantly contributes to meeting the human iodine recommended daily intake, which ranges from $70 \mu \mathrm{g} / \mathrm{d}$ for infants to 200 $\mu \mathrm{g} / \mathrm{d}$ for lactating women. The fulfilment of iodine recommended daily intake is fundamental to prevent serious clinical diseases such as cretinism in infants and goiter in adults. In the present study iodine content was measured in raw and processed commercial cow milk, as well as in raw buffalo, goat, sheep, and donkey milk. Iodine extraction was based on $0.6 \%$ (vol/vol) ammonia, whereas iodine detection and quantification were carried out through an inductively coupled plasma mass spectrometer analyzer. Among processed commercial cow milk, partially skimmed pasteurized milk had the greatest iodine content $(359.42 \mu \mathrm{g} / \mathrm{kg})$ and raw milk the lowest $(166.92 \mu \mathrm{g} / \mathrm{kg})$. With regard to the other dairy species, the greatest iodine content was found in raw goat milk $(575.42 \mu \mathrm{g} / \mathrm{kg})$, followed by raw buffalo $(229.82 \mu \mathrm{g} / \mathrm{kg})$, sheep $(192.64 \mu \mathrm{g} / \mathrm{kg})$, and donkey milk $(7.06 \mu \mathrm{g} / \mathrm{kg})$. Repeatability of milk iodine content, calculated as relative standard deviation of 5 measurements within a day or operator, ranged from 0.96 to $1.84 \%$ and 0.72 to $1.16 \%$, respectively. The overall reproducibility of milk iodine content, calculated as relative standard deviation of 45 measurements across $3 \mathrm{~d}$ of analyses and 3 operators, was $4.01 \%$. These results underline the precision of the proposed analytical method for the determination of iodine content in milk. Key words: milk iodine, repeatability, reproducibility, technological treatment, dairy species

\footnotetext{
Received November 5, 2018.

Accepted February 3, 2019.

*Corresponding author: vania.vigolo@studenti.unipd.it
}

\section{INTRODUCTION}

Iodine is a fundamental element for human health, with particular regard to thyroid activity and thyroid hormone functionality (Schomburg and Köhrle, 2008). Iodine is involved in direct and indirect regulation of a wide array of cellular metabolic pathways and plays a primary role in the regular development of fetus and in infant growth (Underwood, 1997). Dietary intake is the unique source of iodine, and apart from iodized salt, iodine-rich foods are sea fish, crustaceans, milk, and dairy products. The recommended daily intake for humans depends on age and physiological status, and ranges from $70 \mu \mathrm{g} / \mathrm{d}$ for infants to $200 \mu \mathrm{g} / \mathrm{d}$ for lactating women (Zimmermann and Andersson, 2011; EFSA, 2014). Low iodine intake leads to poor development of neurological and physical functions in children, as well as to serious clinical outcomes such as goiter in adults (EFSA, 2014). Because less seafood is being consumed for cultural, economic, and health reasons (Oken et al., 2003; Verbeke et al., 2007), iodized salt, milk, and dairy products have become the major sources of iodine in many European countries (Girelli et al., 2004; Watutantrige Fernando et al., 2013).

Iodine content in cow milk is mostly influenced by sanitizers used for teat dipping procedures (Flachowsky et al., 2014; van der Reijden et al., 2018) and iodine level in feed (Norouzian and Azizi, 2013). The latter, in turn, might be highly variable according to season, farming system, dietary supplements, and level of iodine antagonists (van der Reijden et al., 2018). Supplementing iodine rates in feedstuffs has positive effects on animal health as it is necessary for adequate thyroxin hormone activity, allowing normal fetus development and calf growth (Weiss et al., 2015). van der Reijden et al. (2018) observed that the use of iodine-containing disinfectant was associated with an increase of about $40 \mu \mathrm{g} / \mathrm{L}$ of iodine content in bulk milk. Schöne et al. (2009) reported that doses of $0.2,1.3,5.1$, and 10.1 $\mathrm{mg}$ of iodine supplement per $\mathrm{kg}$ of DM are reflected in 
increased milk iodine content, which averaged 101, 343, 1,215 , and $2,762 \mu \mathrm{g} / \mathrm{kg}$, respectively.

Given the importance of milk and dairy product consumption to achieve the daily iodine requirement in humans, some methods for iodine quantification in milk have been reported (Hedayati et al., 2007; Reid et al., 2008), but very few have described a simple extraction protocol and validation procedure to quantify iodine. Even less information is available with regard to the accuracy and sensitivity of available methods. Furthermore, even if iodine content in cow milk has been previously studied (Sanchez and Szpunar, 1999; Hedayati et al., 2007; Walther et al., 2018), little information on iodine content in processed milk (Stevenson et al., 2018) and in milk of dairy species other than cows is available in the literature. Therefore, the objective of the present study was to validate a simple, fast, and robust gold standard method based on alkaline extraction and inductively coupled plasma (ICP) MS for the quantification of iodine in raw and processed commercial cow milk, and in raw buffalo, goat, sheep, and donkey milk.

\section{MATERIALS AND METHODS}

\section{Reagents and Analytical Apparatus}

Ultrapure $30 \%$ ammonia (vol/vol) was purchased from Nova Chimica (Cinisello Balsamo, Italy). Ultrapure water $\left(18.3 \mathrm{M} \Omega / \mathrm{cm}\right.$ resistivity at $\left.25^{\circ} \mathrm{C}\right)$ was produced with Sartorius Arium 611 UV (Monza Brianza, Italy). Iodine used for calibration curves and rhodium used as internal standard were purchased from SigmaAldrich (St. Louis, MO) at the highest available purity. Reference certified skim milk powder ERM BD150 was purchased from the European Joint Research Centre (Geel, Belgium).

Milk samples were analyzed for fat, protein, casein, lactose, and MUN content using a MilkoScan FT6000 (Foss Electric A/S, Hillerød, Denmark), and for SCC using a Fossomatic (Foss Electric A/S, Hillerød, Denmark) in the laboratory of the Breeders Association of Veneto Region (ARAV, Padova, Italy). Milk iodine extraction was carried out in the laboratory of the Department of Agronomy, Food, Natural Resources, Animals and Environment of the University of Padova (Legnaro, Italy). Iodine detection and quantification were carried out through an ICP-MS analyzer (Spectro MS, Spectro Analytical Instruments, Kleve, Germany) in the laboratory of Eurolab (Bassano del Grappa, Italy).

All solutions and solvents, including 30\% ammonia and ultrapure water, were tested for iodine contamina- tion through ICP-MS analyses. In both reagents, iodine content was lower than the limit of detection of the instrument.

\section{Sample Collection and Preparation}

Milk samples were collected between May and June 2018. Bulk cow raw milk $(\mathbf{R M})$ samples $(\mathrm{n}=5)$ were purchased in 5 different vending machines ( $\mathrm{Pa}$ dova, Italy). Commercial processed cow milk samples, namely whole pasteurized milk $(\mathbf{W M}, \mathrm{n}=5)$, partially skimmed pasteurized milk $(\mathbf{S M}, \mathrm{n}=5)$, whole UHT milk (WUM, $\mathrm{n}=5$ ), and partially skimmed UHT milk (SUM, $\mathrm{n}=5$ ), were purchased in local stores (Padova, Italy). In addition, bulk buffalo $(\mathrm{n}=5)$, sheep $(\mathrm{n}=5)$, goat $(\mathrm{n}=5)$, and donkey $(\mathrm{n}=2) \mathrm{RM}$ samples were collected in different farm tanks (Roma, Italy).

A solution of $0.6 \%$ ammonia ( $\mathrm{vol} / \mathrm{vol}$ ) was prepared by diluting $20 \mathrm{~mL}$ of $30 \%$ ammonia in ultrapure water, up to $1 \mathrm{~L}$ of final volume. To promote homogenization, milk samples were warmed at room temperature for 1 $\mathrm{h}$, gently inverted for 20 times, and successively diluted $(1: 24)$ in $0.6 \%$ ammonia solution in disposable $50-\mathrm{mL}$ plastic tubes. The mixture was incubated in a water bath at $90^{\circ} \mathrm{C}$ for $1 \mathrm{~h}$ to promote iodine extraction. After cooling at room temperature, samples were filtered using a $0.45-\mu \mathrm{m}$ syringe filter. Finally, $5 \mathrm{~mL}$ of the filtered solution was diluted $(1: 1)$ in $0.6 \%$ ammonia, up to a final volume of $10 \mathrm{~mL}$. The resulting solution was 50fold diluted compared with the starting milk to keep expected sample salinity below $0.2 \%$, as recommended for ICP-MS trials (Beauchemin, 1999). Overall, milk sample preparation took about $1.5 \mathrm{~h}$ for a batch of 20 samples.

\section{lodine Detection and Quantification}

Instrument settings, chemical parameters, and physical conditions adopted for ICP-MS analyses (Table 1) followed the recommendations provided by Spectro ICP-MS Report (2012). Standard solutions were prepared freshly on each day of analysis in $0.6 \%$ ammonia, and iodine quantification was obtained with 5 -point calibration curves $\left(\mathrm{R}^{2} \geq 0.99\right.$; i.e., $0,1,10,20$, and 40 $\mu \mathrm{g} / \mathrm{L})$. The same standards were measured after each quantification round to check the effective stability of the analysis. All samples and iodine standard solutions were added with $10 \mu \mathrm{L}$ of $1 \mathrm{mg} / \mathrm{kg}$ rhodium solution as internal standard, to cope with the underestimation due to the losses of the target element. Five technical replicates were performed for each sample as well as for each standard solution used for calibration. Therefore, iodine quantification was calculated as the mean value 
Table 1. Parameter settings of inductively coupled plasma emission mass spectrometer analyzer for iodine detection and quantification in milk

\begin{tabular}{ll}
\hline Parameter & Setting \\
\hline Power & $1,425 \mathrm{~W}$ \\
Cool gas flow rate & $12 \mathrm{~L} / \mathrm{min}$ \\
Auxiliary gas flow rate & $1.2 \mathrm{~L} / \mathrm{min}$ \\
Nebulizer flow rate & $0.92 \mathrm{~L} / \mathrm{min}$ \\
Sample aspiration rate & $1 \mathrm{~mL} / \mathrm{min}$ \\
Sample cone & Nickel \\
Spray chamber & Cyclonic (baffled) \\
Plasma torch & Quartz, fixed $1.5-\mathrm{mm}$ injector tube \\
Base interval/integration time & $20 \mathrm{~ms} / 30 \mathrm{~s}$ \\
Technical replicates & 5 \\
\hline
\end{tabular}

of 5 technical replicates, both for milk samples and iodine standard solutions. Relative standard deviation calculated on technical replicates was defined as instrumental repeatability (Khan et al., 2014).

\section{Method Validation}

Time-related repeatability was defined as the relative standard deviation $\left(\mathbf{R S D}_{\mathbf{r}}\right)$ of 5 consecutive measurements on 5 aliquots of the same milk sample, separately processed within the same day. Time-related reproducibility was calculated as the relative standard deviation $\left(\mathbf{R S D}_{\mathbf{R}}\right)$ of 15 measurements on 15 aliquots of the same milk sample, separately processed after 24,48 , and 72 h. Similarly, operator-related repeatability was assessed as $\mathrm{RSD}_{\mathrm{r}}$ of 5 consecutive measurements on 5 aliquots of the same milk sample, separately processed by the same person. Operator-related reproducibility was assessed as the $\mathrm{RSD}_{\mathrm{R}}$ of 15 measurements on 15 aliquots of the same milk sample, separately processed by 3 different operators who handled 5 aliquots each (Franzoi et al., 2018; Niero et al., 2018a). Horwitz and Horwitz ratios (HorRat) were used as comparison between measured and expected reproducibility values. Horwitz value represents the expected RSD in reproducibility conditions, whereas HorRat is the ratio between the observed $\mathrm{RSD}_{\mathrm{R}}$ and the Horwitz value. The overall relative standard deviation $\left(\mathbf{R S D}_{\mathbf{O}}\right)$ was calculated on iodine quantification carried out by 3 different operators, who handled 5 experimental replicates in 3 different days of analyses, for a total of 45 measurements on 45 aliquots. Thus, $\mathrm{RSD}_{\mathrm{O}}$ express the overall method reproducibility (Landon et al., 2017).

For recovery trials and calculation, $200 \mathrm{mg}$ of certified skim milk powder was dissolved in $20 \mathrm{~mL}$ of $0.6 \%$ ammonia solution and gently shaken for $10 \mathrm{~min}$ before being processed as previously described. Five aliquots were analyzed within $1 \mathrm{~d}$, and for 3 consecutive days. Relative standard deviation of repeatability and $\mathrm{RSD}_{\mathrm{R}}$ were calculated within day and across $3 \mathrm{~d}$ of analyses, as previously described for milk samples. Recovery was expressed as the percentage ratio between measured and certified iodine value (Franzoi et al., 2018; Niero et al., 2018a).

Limit of detection (LOD; expressed as $\mu \mathrm{g} / \mathrm{kg}$ ), was assessed using 10 independent blank measurements and calculated as

$$
\mathrm{LOD}=2 \times \mathrm{t} 95 \times \sigma \times(1+1 / \mathrm{n})^{1 / 2},
$$

where t95 is the Student's 95\% 1-sided confidence interval, $\sigma$ is the standard deviation of the blank measurements at the same interval of iodine signal normalized for the method dilution, and $\mathrm{n}$ is the number of blank measurements (Todorov and Gray, 2016). Limit of quantification (LOQ; expressed as $\mu \mathrm{g} / \mathrm{kg}$ ), was calculated as $3 \times$ LOD (Armbruster and Pry, 2008).

\section{RESULTS AND DISCUSSION}

\section{Variation of lodine Content Across Technological Treatments}

Descriptive statistics for iodine content, milk chemical composition, MUN, and SCC in raw and processed cow milk are reported in Table 2. Partially skimmed pasteurized milk had the greatest iodine content (359.42 $\mu \mathrm{g} / \mathrm{kg})$, followed by WUM $(305.24 \mu \mathrm{g} / \mathrm{kg})$, SUM $(266.60$ $\mu \mathrm{g} / \mathrm{kg}), W M(253.53 \mu \mathrm{g} / \mathrm{kg})$, and RM $(166.92 \mu \mathrm{g} / \mathrm{kg})$. To the best of our knowledge there are no scientific studies dealing with milk iodine content in relation to milk chemical composition. Because iodine compounds are soluble in water (Dahl et al., 2003; Moschini et al., 2010), it is likely that milk iodine increases in partially skim milk, having greater soluble fraction on a volume to volume ratio as a result of the skimming process (Niero et al., 2017). Further than soluble or inorganic fraction, results of the present study suggest that milk iodine might be partially associated with casein micelles, as observed by Franzoi et al. (2018) and Visentin et al. (2018) who reported favorable correlations between milk proteins and major milk minerals. Overall, the average content of iodine in WUM observed in the present study was close to values reported by Stevenson et al. (2018), slightly lower than values reported by Payling et al. (2015), and slightly higher than findings of Dahl et al. (2003). Conversely, the overall iodine content in WM was considerably lower than that reported by Payling et al. (2015) and Stevenson et al. (2018), whereas the average iodine contents in RM and WUM were from 1.28- to 2.83-fold and 2.26- to 4.77-fold those reported by Walther et al. (2018). 


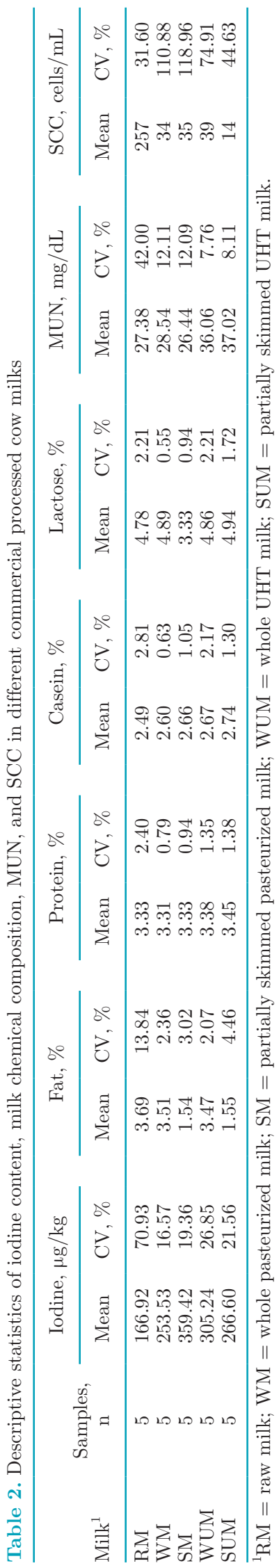

The greatest coefficient of variation $(\mathbf{C V})$ for iodine content was observed for cow RM (70.93\%), whereas processed milk showed considerably lower CV, from 16.57 to $26.85 \%$ for WM and WUM, respectively. As expected, the greatest CV for gross milk composition, including fat, protein, casein, lactose, and MUN content was calculated for RM, whereas lower CV was observed for processed and standardized milk samples. Thus, it is likely that the variation of milk iodine content is associated with the variation of milk chemical composition (and vice versa), rather than to the pasteurization procedures or to the UHT treatments; this agrees with previous findings of Walther et al. (2018). Overall, it cannot be excluded that factors such as animal feeding, farming conditions, herd management, and sanitizers used for pre- and postdipping procedures might have affected milk iodine concentration. Nevertheless, because bulk milk from different herds is mixed to obtain standardized commercial milk samples, we might assume that the aforementioned sources of variation were smoothed to a negligible extent.

\section{Variation of lodine Content Across Dairy Species}

Descriptive statistics for iodine content, milk chemical composition, MUN, and SCC in bulk buffalo, sheep, goat, and donkey RM are reported in Table 3. Buffalo, sheep, and goat milk showed similar composition to that reported by Niero et al. (2018b) in individual milk samples. In agreement with previous findings of Salimei et al. (2004), donkey RM had relatively low fat (0.65\%) and protein content $(1.78 \%)$, and comparatively high lactose content (6.27\%). Iodine content in buffalo, sheep, goat, and donkey milk averaged 229.82, 192.64, 575.42 , and $7.06 \mu \mathrm{g} / \mathrm{kg}$, respectively. Thus, ruminant dairy species, including cow, buffalo, sheep, and goat showed iodine content in the same order of magnitude. On the other hand, notably lower iodine content was observed for donkey milk, being the only monogastric species considered in the present study. Within ruminants, the greatest iodine content observed in goat RM was associated with the lowest fat percentage. Thus, the hypothesis of greater milk iodine content in low fat milk might be confirmed also in ruminant dairy species other than cow. Differences in iodine contents across species are likely due to animal diet and physiology, nutrient absorption and transportation, herd management, farming systems, and milking procedures, as reported also for major milk minerals (Flynn, 1992).

Among dairy species other than cow, buffalo RM showed the greatest CV (103.65\%), followed by goat RM (50.41\%) and sheep RM (38.40\%). Such a variability within dairy species is similar to that observed 


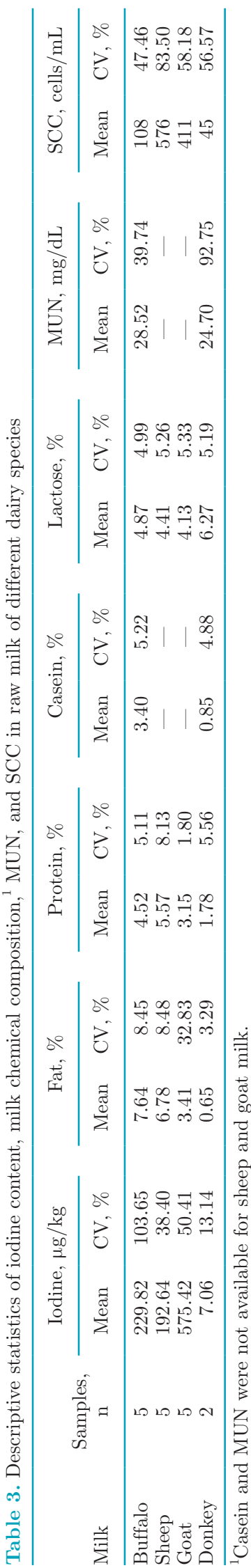

for cow RM, but considerably wider compared with processed cow milk samples (Table 2).

\section{Repeatability}

Instrumental repeatability ranged from 0.01 to $2.01 \%$. Table 4 reports mean iodine content and $\mathrm{RSD}_{\mathrm{r}}$, calculated within each day of analysis and each operator on 5 aliquots of the same cow RM sample. Five aliquots were handled in the first day of analysis (d 1) by the first operator (operator 1); the mean milk iodine content was $65.82 \mu \mathrm{g} / \mathrm{kg}$ and the $\mathrm{RSD}_{\mathrm{r}}$ was $0.96 \%$. Relative standard deviation of repeatability within day of analysis ranged from $0.96 \%$ (d 1) to $1.84 \%$ (d 2). Relative standard deviation of repeatability within operator was even lower than that within day of analysis, ranging from 0.72 to $1.16 \%$ for operator 3 and operator 2 , respectively. Table 5 reports mean iodine content and $\mathrm{RSD}_{\mathrm{r}}$, calculated within $1 \mathrm{~d}$ of analysis on 5 aliquots of 1 cow WM, SM, WUM, and SUM sample, and 1 buffalo, sheep, goat, and donkey RM sample. Among commercial cow milk samples, the greatest repeatability was achieved for WUM (0.37\%). Slightly lower repeatabilities were obtained for SUM (1.07\%), SM (1.11\%), and WM (2.49\%). Relative standard deviation of repeatability calculated on RM of other dairy species ranged from 1.07 to $8.81 \%$ for goat and donkey milk, respectively.

Overall, $\mathrm{RSD}_{\mathrm{r}}$ values reflected fulfilling repeatability for iodine quantification, being lower than $5.48 \%$ for all milk samples, with the only exception of donkey RM. Relative standard deviations of repeatability observed in the present study were close to those obtained by other authors for the quantification of whey proteins and milk tocopherols through HPLC (Sturaro et al., 2016; Niero et al., 2018a), for the determination of soluble and colloidal milk minerals through inductively coupled plasma optical emission spectrometry (Franzoi et al., 2018), and for the assessment of milk total antioxidant activity through the spectrophotometric method (Niero et al., 2017). The undue RSD observed for donkey RM is likely due to the relatively low iodine content, being greater than method LOD but lower than method LOQ (Armbruster and Pry, 2008).

\section{Reproducibility}

Relative standard deviation of reproducibility, Horwitz $\mathrm{RSD}_{\mathrm{R}}$, and HorRat calculated on 15 aliquots of the same cow RM sample across $3 \mathrm{~d}$ of analyses and across 3 operators are reported in Table 4 . The $\mathrm{RSD}_{\mathrm{R}}$ calculated across $3 \mathrm{~d}$ of analyses was greater than $\mathrm{RSD}_{\mathrm{R}}$ across 3 different operators, being 2.67 and $1.02 \%$, respectively. Therefore, a slight decline in accuracy was found across 
Table 4. Mean $(\mu \mathrm{g} / \mathrm{kg})$, relative standard deviation of repeatability $\left(\mathrm{RSD}_{\mathrm{r}}, \% ; \mathrm{n}=5\right)$ within day and operator, relative standard deviation of reproducibility $\left(\mathrm{RSD}_{\mathrm{R}}, \% ; \mathrm{n}=15\right)$, expected Horwitz $\mathrm{RSD}_{\mathrm{R}}(\%)$, and Horwitz ratio (HorRat) across days and operators for iodine content in cow raw milk

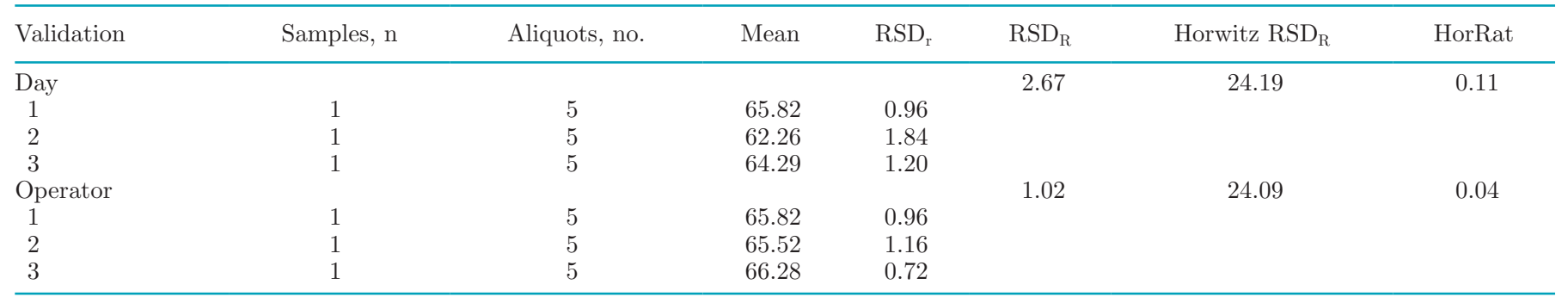

days when compared with the accuracy observed within day, in accordance with the results of Niero et al. (2017). Nevertheless, RSD $_{R}$ values lower than $22.00 \%$ are considered acceptable for chemicals between 10 and $100 \mu \mathrm{g} / \mathrm{kg}$ (Thompson and Fearn, 1996). On the other hand, reproducibility performances calculated across operators did not evidence notable discrepancies when compared with the within operator repeatability. Such findings suggest that the greatest source of variability for milk iodine analyses is the day of analysis, whereas almost negligible effects are associated with the operator in charge of milk iodine extraction and quantification. Horwitz ratios calculated across days and operators were 0.11 and 0.04 , respectively. Since HorRat values lower than 1 are considered acceptable (Horwitz and Albert, 2006), results of the present study indicate that the method proposed to quantify milk iodine content is reproducible.

Finally, $\mathrm{RSD}_{\mathrm{O}}$ calculated on quantification obtained by 3 different operators, who handled 5 aliquots in 3 different days of analyses (for a total of 45 experimental replicates), was $4.01 \%$, with an overall HorRat value of 0.17. The $\mathrm{RSD}_{\mathrm{O}}$ was greater than $\mathrm{RSD}_{\mathrm{r}}$ and $\mathrm{RSD}_{\mathrm{R}}$, and this was somewhat expected since $\mathrm{RSD}_{\mathrm{O}}$ summarizes

Table 5. Mean $(\mu \mathrm{g} / \mathrm{kg})$ and relative standard deviation of repeatability $\left(\mathrm{RSD}_{\mathrm{r}}, \% ; \mathrm{n}=5\right)$ within day for iodine content in processed commercial cow milk, and raw buffalo, sheep, goat, and donkey milk

\begin{tabular}{lccrc}
\hline Milk $^{1}$ & Samples, $\mathrm{n}$ & Aliquots, no. & Mean & RSD $_{\mathrm{r}}$ \\
\hline Cow milk & 1 & 5 & 65.82 & 0.96 \\
RM & 1 & 5 & 270.43 & 2.49 \\
WM & 1 & 5 & 366.59 & 1.11 \\
SM & 1 & 5 & 254.38 & 0.37 \\
WUM & 1 & 5 & 313.86 & 1.07 \\
SUM & 1 & 5 & 178.29 & 2.81 \\
Buffalo RM & 1 & 5 & 243.16 & 5.48 \\
Sheep RM & 1 & 5 & 591.06 & 1.07 \\
Goat RM & 1 & 5 & 7.26 & 8.81 \\
Donkey RM & 1 & 5 &
\end{tabular}

${ }^{1} \mathrm{RM}=$ raw milk; $\mathrm{WM}=$ whole pasteurized milk; $\mathrm{SM}=$ partially skimmed pasteurized milk; WUM = whole UHT milk; SUM = partially skimmed UHT milk. all sources of variability, including all days of analysis and all operators together. Still, RSD below $5 \%$ is considered acceptable (Niero et al., 2017), meaning that extraction and quantification of milk iodine can be carried out by different operators in different days, affecting to a minor extent the reliability of analytical process (Thompson and Fearn, 1996).

\section{Recovery, $L O D$, and $L O Q$}

Recoveries calculated on certified skim milk within single day of analyses varied between 87.41 and $98.90 \%$, whereas the overall recovery calculated as the mean value across $3 \mathrm{~d}$ of analyses was $92.55 \%$. Overall, the iodine content determined in the present study for certified skim milk was in accordance with the $95 \%$ confidence interval reported in reference material certificate of analysis. Relative standard deviation of repeatability for iodine quantification on certified skim milk ranged from 3.06 to $5.50 \%$, whereas $\mathrm{RSD}_{\mathrm{R}}$ across $3 \mathrm{~d}$ of analyses was $6.47 \%$. Recovery results, as well as $\mathrm{RSD}_{\mathrm{r}}$ and $\mathrm{RSD}_{\mathrm{R}}$ calculated on recovery trials, were comparable to findings of Dahl et al. (2003) who studied iodine content in Norwegian milk and dairy products.

Limit of detection of iodine content calculated on known standard solution and on 50-fold diluted milk sample was $0.1 \mu \mathrm{g} / \mathrm{kg}$. Therefore, iodine LOD in the entire milk sample was equal to $5 \mu \mathrm{g} / \mathrm{kg}$. Limit of quantification of iodine calculated as 3 times the LOD was $0.3 \mu \mathrm{g} / \mathrm{kg}$ on standard solution and on 50-fold diluted sample, and $15 \mu \mathrm{g} / \mathrm{kg}$ for the entire milk sample. Other than iodine content in donkey milk, the minimum content of iodine observed in the present study was 7.23-fold that of LOD, and 2.41-fold that of LOQ; thus, adequate confidence level and sensitivity may be assumed.

\section{CONCLUSIONS}

The present study provided a fast and reliable protocol for iodine quantification in processed commercial 
and raw cow milk, and in raw buffalo, sheep, goat, and donkey milk. Milk sample preparation is based on ammonia, takes about $1.5 \mathrm{~h}$ for a batch of 20 samples, and does not require specific laboratory equipment such as a microwave digester. The method was repeatable and reproducible among different days of analyses and operators, and can be used for quantification of samples containing more than $15 \mu \mathrm{g}$ of iodine per $\mathrm{kg}$ of milk. The variation of iodine content in commercial cow milk was likely related to milk chemical composition, rather than to technological treatments. Across the 5 dairy species considered in our study, raw goat and donkey milk showed the greatest and the lowest iodine content, respectively. Further research is needed to gain knowledge on how and to which extent milk iodine content is driven by herd management including feeding strategies and milking procedures, environmental effects, breed, and animal physiological status such as lactation stage and parity order.

\section{ACKNOWLEDGMENTS}

The authors thank the laboratory of the Breeders Association of Veneto Region (ARAV, Padova, Italy), Eurolab (Bassano del Grappa, Vicenza, Italy), and Luciano Magro and Massimo Cagnin (University of Padova) for technical support.

\section{REFERENCES}

Armbruster, D. A., and T. Pry. 2008. Limit of blank, limit of detection and limit of quantitation. Clin. Biochem. Rev. 29:S49-S52.

Beauchemin, D. 1999. Encyclopedia of Spectroscopy and Spectrometry. 2nd ed. Academic Press, Oxford, UK.

Dahl, L., J. A. Opsahl, H. M. Meltzer, and K. Julshamn. 2003. Iodine concentration in Norwegian milk and dairy products. Br. J. Nutr. 90:679-685.

EFSA. 2014. Scientific opinion on the Dietary Reference Values for iodine. EFSA J. 12:3660-3717.

Flachowsky, G., K. Franke, U. Meyer, M. Leiterer, and F. Schöne. 2014. Influencing factors on iodine content of cow milk. Eur. J. Nutr. 53:351-365.

Flynn, A. 1992. Minerals and trace elements in milk. Adv. Food Nutr. Res. 36:209-252.

Franzoi, M., G. Niero, M. Penasa, M. Cassandro, and M. De Marchi. 2018. Technical note: Development and validation of a new method for the quantification of soluble and micellar calcium, magnesium, and potassium in milk. J. Dairy Sci. 101:1883-1888.

Girelli, M. E., P. Coin, C. Mian, D. Nacamulli, L. Zambonin, M. Piccolo, A. Vianello-Dri, F. Gottardo, and B. Busnardo. 2004. Milk represents an important source of iodine in schoolchildren of the Veneto region, Italy. J. Endocrinol. Invest. 27:709-713.

Hedayati, M., A. Ordookhani, M. S. Daneshpour, and F. Azizi. 2007. Rapid acid digestion and simple microplate method for milk iodine determination. J. Clin. Lab. Anal. 21:286-292.

Horwitz, W., and R. Albert. 2006. The Horwitz ratio (HorRat): A useful index of method performance with respect to precision. J. AOAC Int. 89:1095-1109.

Khan, N., I. S. Jeong, I. M. Hwang, J. S. Kim, S. H. Choi, E. Y. Nho, J. Y. Choi, K. S. Park, and K. S. Kim. 2014. Analysis of minor and trace elements in milk and yogurts by inductively coupled plasmamass spectrometry (ICP-MS). Food Chem. 147:220-224.

Landon, G., C. Bouvier-Capely, A. Legrand, T. Sontag, G. Finance, M. Saint-Hilaire, F. Rebière, X. Millot, V. Renaud-Salis, and M. Agarande. 2017. Validation and comparison of two calibration methods for the measurement of stable iodine in the urinary matrix by ICP-MS: Standard addition vs. external calibration. Am. J. Anal. Chem. 8:245-263.

Moschini, M., M. Battaglia, G. M. Beone, G. Piva, and F. Masoero. 2010. Iodine and selenium carry over in milk and cheese in dairy cows: Effect of diet supplementation and milk yield. Animal 4:147155.

Niero, G., S. Currò, A. Costa, M. Penasa, M. Cassandro, C. Boselli, G. Giangolini, and M. De Marchi. 2018b. Short communication: Phenotypic characterization of total antioxidant activity of buffalo, goat, and sheep milk. J. Dairy Sci. 101:4864-4868.

Niero, G., M. Penasa, J. Berard, M. Kreuzer, M. Cassandro, and M. De Marchi. 2018a. Technical note: Development and validation of an HPLC method for the quantification of tocopherols in different types of commercial cow milk. J. Dairy Sci. 101:6866-6871.

Niero, G., M. Penasa, S. Currò, A. Masi, A. R. Trentin, M. Cassandro, and M. De Marchi. 2017. Development and validation of a near infrared spectrophotometric method to determine total antioxidant activity of milk. Food Chem. 220:371-376.

Norouzian, M., and F. Azizi. 2013. Factors affecting iodine content in dairy cow's milk - A review. Eur. J. Food Res. Rev. 3:63-73.

Oken, E., K. P. Kleinman, W. E. Berland, S. R. Simon, J. W. RichEdwards, and M. W. Gillman. 2003. Decline in fish consumption among pregnant women after a national mercury advisory. Obstet. Gynecol. 102:346-351.

Payling, L. M., D. T. Juniper, C. Drake, C. Rymer, and D. I. Givens 2015. Effect of milk type and processing on iodine concentration of organic and conventional winter milk at retail: implications for nutrition. Food Chem. 178:327-330.

Reid, H. J., A. A. Bashammakh, P. S. Goodall, M. R. Landon, C. O'Connor, and B. L. Sharp. 2008. Determination of iodine and molybdenum in milk quadrupole ICP-MS. Talanta 75:189-197.

Salimei, E., F. Fantuz, R. Coppola, B. Chiofalo, P. Polidori, and G. Varisco. 2004. Composition and characteristics of ass's milk. Anim. Res. 53:67-78.

Sanchez, L. F., and J. Szpunar. 1999. Speciation analysis for iodine in milk by size-exclusion chromatography with inductively coupled plasma mass spectrometric detection (SEC-ICP MS). J. Anal. At. Spectrom. 14:1697-1702.

Schomburg, L., and J. Köhrle. 2008. On the importance of selenium and iodine metabolism for thyroid hormone biosynthesis and human health. Mol. Nutr. Food Res. 52:1235-1246.

Schöne, F., M. Leiterer, P. Lebzien, D. Bemmann, M. Spolders, and G. Flachowsky. 2009. Iodine concentration of milk in a dose-response study with dairy cows and implications for consumer iodine intake. J. Trace Elem. Med. Biol. 23:84-92.

Spectro ICP-MS Report. 2012. The analysis of drinking water. 3rd ed SPECTRO Analytical Instruments, Kleve, Germany.

Stevenson, M. C., C. Drake, and D. I. Givens. 2018. Further studies on the iodine concentration of conventional, organic and UHT semiskimmed milk at retail in the UK. Food Chem. 239:551-555.

Sturaro, A., M. De Marchi, A. Masi, and M. Cassandro. 2016. Quantification of whey proteins by reversed phase-HPLC and effectiveness of mid-infrared spectroscopy for their rapid prediction in sweet whey. J. Dairy Sci. 99:68-76.

Thompson, M., and T. Fearn. 1996. What exactly is fitness for purpose in analytical measurement? Analyst (Lond.) 121:275-278.

Todorov, T. I., and P. J. Gray. 2016. Analysis of iodine in food samples by inductively coupled plasma-mass spectrometry. Food Addit. Contam. Part A Chem. Anal. Control Expo. Risk Assess. $33: 282-290$.

Underwood, E. J. 1997. Trace Elements in Human and Animal Nutrition. 4th ed. Academic Press, New York, NY.

van der Reijden, O. L., V. Galetti, M. Hulmann, A. Krzystek, M. Haldimann, P. Schlegel, E. Manzocchi, J. Berard, M. Kreuzer, M. B. 
Zimmermann, and I. Herter-Aeberli. 2018. The main determinants of iodine in cows' milk in Switzerland are farm type, season and teat dipping. Br. J. Nutr. 119:559-569.

Verbeke, W., F. Vanhonacker, I. Sioen, J. Van Camp, and S. De Henauw. 2007. Perceived importance of sustainability and ethics related to fish: a consumer behavior perspective. Ambio 36:580585 .

Visentin, G., M. Penasa, G. Niero, M. Cassandro, and M. De Marchi. 2018. Phenotypic characterisation of major mineral composition predicted by mid-infrared spectroscopy in cow milk. Ital. J. Anim. Sci. 17:549-556.

Walther, B., D. Wechsler, P. Schlegel, and M. Haldimann. 2018. Iodine in Swiss milk depending on production (conventional versus organic) and on processing (raw versus UHT) and the contribution of milk to the human iodine supply. J. Trace Elem. Med. Biol. 46:138-143.

Watutantrige Fernando, S., S. Barollo, D. Nacamulli, D. Pozza, M. Giachetti, F. Frigato, M. Redaelli, G. Zagotto, M. E. Girelli, F. Mantero, and C. Mian. 2013. Iodine status in schoolchildren living in northeast Italy: the importance of iodized-salt use and milk consumption. Eur. J. Clin. Nutr. 67:366-370.

Weiss, W. P., D. J. Wyatt, D. H. Kleinschmit, and M. T. Socha. 2015. Effect of including canola meal and supplemental iodine in diets of dairy cows on short-term changes in iodine concentrations in milk. J. Dairy Sci. 98:4841-4849.

Zimmermann, M. B., and M. Andersson. 2011. Prevalence of iodine deficiency in Europe in 2010. Ann. Endocrinol. (Paris) 72:164-166. 